\title{
Um método simples de caracterização de argilominerais por difração de raios $\mathbf{X}$ (A simple method for the characterization of clay minerals by $X$-ray diffraction)
}

\author{
A. P. F. Albers', F. G. Melchiades ${ }^{2}$, R. Machado ${ }^{2}$, J. B. Baldo' , A. O. Boschi ${ }^{2}$ \\ ${ }^{1}$ Universidade do Vale do Paraíba, UNIVAP \\ Praça Candido Dias Castejón, 116, 12245-720, Centro, S. José dos Campos, SP \\ ${ }^{2}$ Universidade Federal de S. Carlos, DEMa \\ Rod. Washington Luiz, km 235, C.P. 676, 13565-905, S. Carlos, SP \\ daob@power.ufscar.br
}

\section{Resumo}

\begin{abstract}
A técnica de difração de raios X tem sido amplamente utilizada para a determinação de fases cristalinas em materiais cerâmicos. Em argilas, a grande quantidade de quartzo e seu elevado grau de orientação dificultam a identificação e caracterização das demais fases presentes. Baseando-se no princípio da sedimentação, é apresentado neste trabalho um método simples e confiável para a determinação de argilominerais em materiais argilosos.
\end{abstract}

Palavras-chave: difração de raios $\mathrm{X}$, argilominerais.

\begin{abstract}
The X-ray diffraction technique has been widely used for the determination of crystalline phases in ceramic materials. The large content and high degree of orientation of quartz in clays pose a problem to the identification and characterization of the remaining phases. A simple and reliable method for the determination of clay minerals in clay materials, based on the sedimentation principle, is presented.
\end{abstract}

Keywords: X-ray diffraction, clay minerals.

\section{INTRODUÇÃO}

Dentre as várias técnicas de caracterização de materiais, a técnica de difração de raios $\mathrm{X}$ é a mais indicada na determinação das fases cristalinas presentes em materiais cerâmicos. Isto é possível porque na maior parte dos sólidos (cristais), os átomos se ordenam em planos cristalinos separados entre si por distâncias da mesma ordem de grandeza dos comprimentos de onda dos raios $\mathrm{X}$.

Ao incidir um feixe de raios $\mathrm{X}$ em um cristal, o mesmo interage com os átomos presentes, originando o fenômeno de difração. A difração de raios X ocorre segundo a Lei de Bragg (Equação A), a qual estabelece a relação entre o ângulo de difração e a distância entre os planos que a originaram (característicos para cada fase cristalina):

$$
\mathrm{n} \lambda=2 \mathrm{~d} \operatorname{sen} \theta
$$

$\mathrm{n}$ : número inteiro

$\lambda$ : comprimento de onda dos raios $\mathrm{X}$ incidentes

$\mathrm{d}$ : distância interplanar

$\theta$ : ângulo de difração

Dentre as vantagens da técnica de difração de raios $\mathrm{X}$ para a caracterização de fases, destacam-se a simplicidade e rapidez do método, a confiabilidade dos resultados obtidos (pois o perfil de difração obtido é característico para cada fase cristalina), a possibilidade de análise de materiais compostos por uma mistura de fases e uma análise quantitativa destas fases.

Ao se caracterizar argilominerais, a utilização da técnica de difração de raios $\mathrm{X}$ torna-se ainda mais indicada, pois uma análise química reportaria os elementos químicos presentes no material, mas não a forma como eles estão ligados. A análise química poderia então ser associada à análise racional, porém os resultados obtidos não apresentam elevada confiabilidade, além deste procedimento não ser indicado para identificar fases polimórficas. A semelhança do comportamento térmico dos argilominerais também descarta a utilização isolada das técnicas termo-diferenciais, que também são mais dispendiosas e demoradas.

Porém na caracterização de argilas, o elevado teor de quartzo da amostra e sua facilidade de orientar-se resultam em picos bem definidos e de grande intensidade desta fase cristalina, prejudicando muitas vezes a identificação e caracterização das demais fases.

Neste trabalho é descrito um procedimento rápido e eficiente para identificar os argilominerais mais comumente encontrados nas argilas nacionais. Tal procedimento minimiza a presença do quartzo e facilita a identificação das demais fases.

\section{MATERIAIS E MÉTODOS}

Os materiais utilizados no presente trabalho são argilas nacionais encontradas facilmente no mercado, as quais serão denominadas $\mathbf{A}, \mathbf{B}, \mathbf{C}$ e $\mathbf{D}$. Tais argilas foram submetidas ao procedimento descrito à seguir para identificação de argilominerais por difração de raios $X$.

Os ensaios de difração de raios $X$ foram realizados em um difratômetro Siemens - modelo D 5000, com velocidade do goniômetro de $1 \% \mathrm{~min}$, tubo de cobre $(\lambda=1,542 \AA)$. 
Procedimento para identificação de argilominerais por difração de raios $X$

A. Procedimento geral

1. Pesar $20,0 \mathrm{~g}$ de argila seca e desagregar em almofariz até granulometria inferior a peneira \# ABNT 200 (abertura de $74 \mathrm{~mm}$ ).

2. Suspender a argila desagregada em $200 \mathrm{~mL}$ de água destilada.

3. Adicionar 5,0 $\mathrm{mL}$ de hidróxido de amônio $\left(\mathrm{NH}_{4} \mathrm{OH}\right)$.

4. Agitar a suspensão e transferir para uma proveta de $250 \mathrm{~mL}$.

5. Deixar a suspensão em repouso durante $24 \mathrm{~h}$.

6. Com o auxílio de uma pipeta retirar a fração fina da suspensão, evitando perturbação da mesma e coleta do material grosseiro depositado.

7. Secar a fração fina da suspensão em estufa a $100{ }^{\circ} \mathrm{C}$, posteriormente desaglomerá-la.

8. Preparar uma suspensão argila-água com concentração de 60,0 $\mathrm{mg}$ de argila por $1 \mathrm{~cm}^{3}$ de água destilada.

9. Retirar com a pipeta $3,0 \mathrm{~mL}$ da suspensão preparada e depositar cuidadosamente sobre uma lâmina de vidro (as dimensões da lâmina devem ser compatíveis com o porta-amostra utilizado no difratômetro). 10. Secar a lâmina em estufa à $100^{\circ} \mathrm{C}$.

11. Realizar o ensaio de difração de raios $\mathrm{X}$, varrendo-se de 2 a $30^{\circ}$ (escala $2 \theta$ ) com velocidade de $1 \% \mathrm{~min}$.

Após o ensaio de difração de raios X, as distâncias interplanares (d) referentes aos picos apresentados no difratograma deverão ser

Tabela I - Distâncias interplanares características [1].

[Table I: Interplanar distance [1].]

\begin{tabular}{ccc}
\hline $\begin{array}{c}\text { Distância } \\
\text { Interplanar }(\AA) \\
\text { (pico principal) }\end{array}$ & $\begin{array}{c}\text { Distância } \\
\text { Interplanar }(\AA) \\
\text { (picos } \\
\text { secundários) }\end{array}$ & Argilomineral \\
\hline 7 & 3,58 & Caulinita \\
\hline 10 & 5,0 e 3,33 & Ilita \\
\hline 14 & 7,$0 ; 4,7$ e 3,5 & Clorita \\
\hline 14 & 7,$0 ; 4,7$ e 3,5 & Clorita expansível \\
\hline 12 ou 14 & 5,1 e 3,5 & Montmorilonita-12 ou 14 \\
\hline 14 & & Vermiculita \\
\hline
\end{tabular}

confrontadas com as distâncias interplanares características de cada fase.

Considerando somente os minerais simples (geralmente presentes nas argilas nacionais), o pico de maior intensidade de cada fase (referentes a direção (001)), bem como os picos secundários, encontram-se na Tabela I.

De acordo com a Tabela I, utilizando-se apenas a reflexão principal, muitas vezes não é possível determinar com segurança o argilomineral presente. Nestes casos, recomenda-se a utilização dos procedimento $\mathrm{B}$ e $\mathrm{C}$, descritos à seguir.

B. Solvatação com etilenoglicol (ou glicerol) - Glicolagem

1. Preparar uma lâmina seguindo o procedimento geral (pode-se empregar a mesma lâmina utilizada anteriormente).

2. Posicionar a lâmina sobre um suporte dentro de um recipiente com tampa (o suporte servirá para que a lâmina não fique apoiada no fundo do recipiente).

3. Adicionar $100 \mathrm{~mL}$ de etilenoglicol (ou glicerol) no fundo do recipiente, impedindo o contato direto do reagente com a lâmina.

4. Tampar o recipiente e colocá-lo na estufa a $90^{\circ} \mathrm{C}$ durante $5 \mathrm{~h}$.

5. Retirada a lâmina da estufa, proceder o ensaio de difração de raios $\mathrm{X}$ (o ensaio deverá ser realizado em no máximo $1 \mathrm{~h}$ após a retirada da lâmina da estufa), varrendo-se de 2 a $15^{\circ}$ (escala $2 \theta$ ) com velocidade de $1 \%$ min.

6. Verificar o deslocamento dos picos em relação ao ensaio anterior e consultar a Tabela II.

Este procedimento baseia-se na capacidade de alguns argilominerais admitirem em sua estrutura ligações com álcoois, e estes por sua vez, com a água. Desta forma, aumenta-se a distância interplanar referentes à direção (001). Como exemplo prático, temse o pico principal da montmorilonita, que passa de 12 ou $14 \AA$ para aproximadamente $17 \AA$, sendo possível distinguí-la da vermiculita, que mantém o pico em $14 \AA$.

C. Aquecimento da amostra

1. Preparar uma lâmina seguindo o procedimento geral (pode-se empregar a mesma lâmina utilizada anteriormente).

2. Colocar a lâmina em uma mufla, aquecendo-a a $500{ }^{\circ} \mathrm{C}$ mantendoa por $2 \mathrm{~h}$.

3. Retirada a lâmina da mufla, proceder o ensaio de difração de raios $\mathrm{X}$, varrendo-se de 2 a $15^{\circ}$ (escala $2 \theta$ ) com velocidade de $1 \% \mathrm{~min}$.

4. Verificar o deslocamento dos picos em relação ao ensaio anterior

Tabela II - Posições referentes aos picos principais (direção(001)) dos argilominerais em condições normais (N), após glicolagem (G)e aquecimento (A) [1]. [Table II: Main diffraction peaks (001) of clay minerals upon normal conditions (N), after treatment with ethylene glycol $(G)$ and after thermal treatment $(A)$ [1].]

\begin{tabular}{cccl}
\hline $\begin{array}{l}\text { Distância Interplanar }(\AA) \\
\text { (condições normais) }\end{array}$ & $\begin{array}{c}\text { Distância Interplanar }(\AA) \\
\text { (após glicolagem) }\end{array}$ & $\begin{array}{c}\text { Distância Interplanar }(\AA) \\
\text { (após aquecimento) }\end{array}$ & Argilomineral \\
\hline 7 & 7 & - & Caulinita \\
\hline 10 & 10 & 10 & Ilita \\
\hline 14 & 14 & 14 & Clorita \\
\hline 14 & 17 & 14 & Clorita expansível \\
\hline 12 & 17 & 10 & Montmorilonita-12 \\
\hline 14 & 17 & 10 & Montmorilonita-14 \\
\hline 14 & 14 & 10 & Vermiculita \\
\hline
\end{tabular}


e consultar a Tabela II.

Neste caso, buscou-se eliminar as moléculas de água adsorvidas nos argilominerais, resultando na redução da distância interplanar referentes à direção (001). Como exemplo prático, novamente temse o pico principal da montmorilonita, que se desloca para $10 \AA$. O mesmo ocorre com o pico da vermiculita.

\section{RESULTADOS E DISCUSSÃO}

A Fig. 1 apresenta o difratograma da argila $\mathbf{A}$, obtido de acordo com o procedimento geral (A).

Comparando-se o difratograma apresentado na Fig. 1 (argila A) e a Tabela I, conclui-se que os dois picos presentes são do argilomineral caulinita. Neste caso, apenas o procedimento geral (A) foi suficiente para determinar o argilomineral presente.

A Fig. 2 apresenta o difratograma da argila $\mathbf{B}$, obtido de acordo

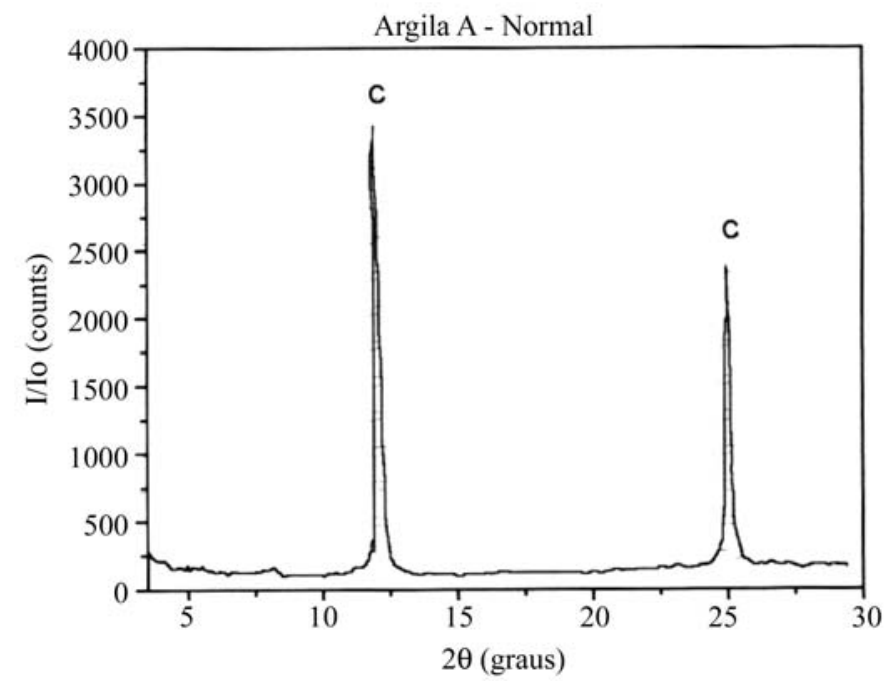

Figura 1: Difratograma da argila A, seguindo o procedimento geral (A). C: caulinita.

[Figure 1: X-ray diffraction pattern of clay A, following procedure (A). C: kaolinite.]

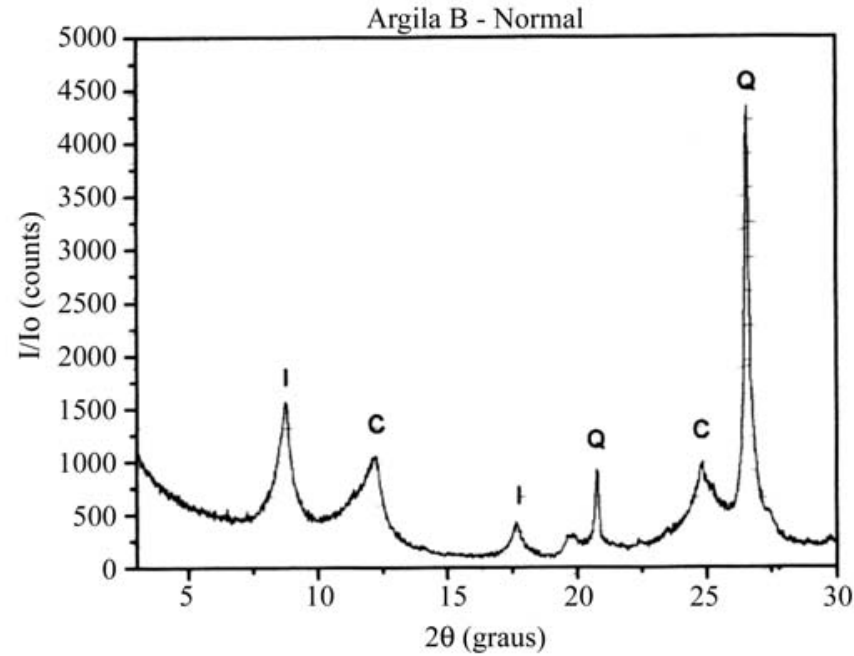

Figura 2: Difratograma da argila B, seguindo o procedimento geral (A). I: ilita, C: caulinita e Q: quartzo.

[Figure 2: X-ray diffraction pattern of clay $\boldsymbol{B}$, following procedure (A). I: illite, $C$ : kaolinite, $Q$ : quartz.]

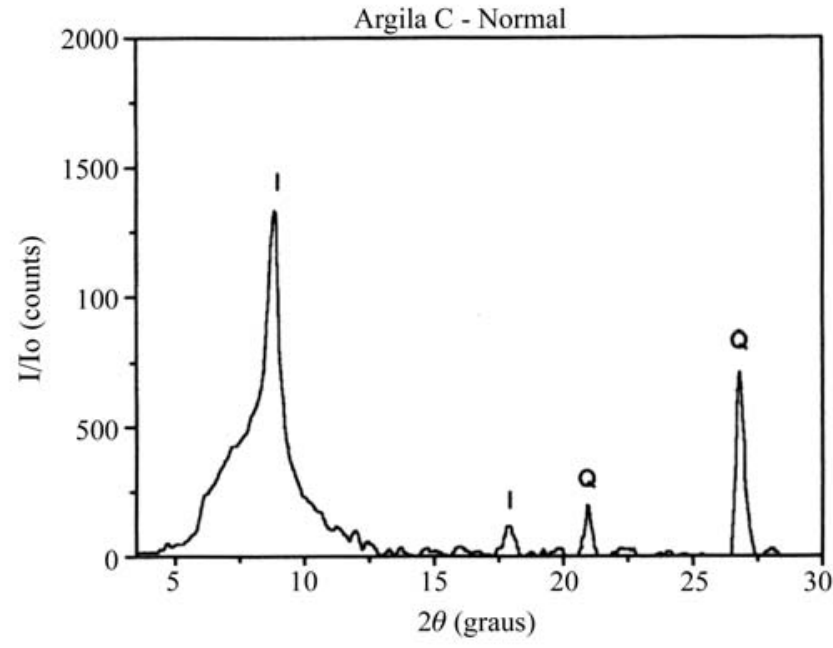

Figura 3: Difratograma da argila $\mathbf{C}$, seguindo o procedimento geral (A). I: ilita, Q: quartzo.

[Figure 3: $X$-ray diffraction pattern of clay $\boldsymbol{C}$, following procedure (A). I: illite, $Q$ : quartz.]

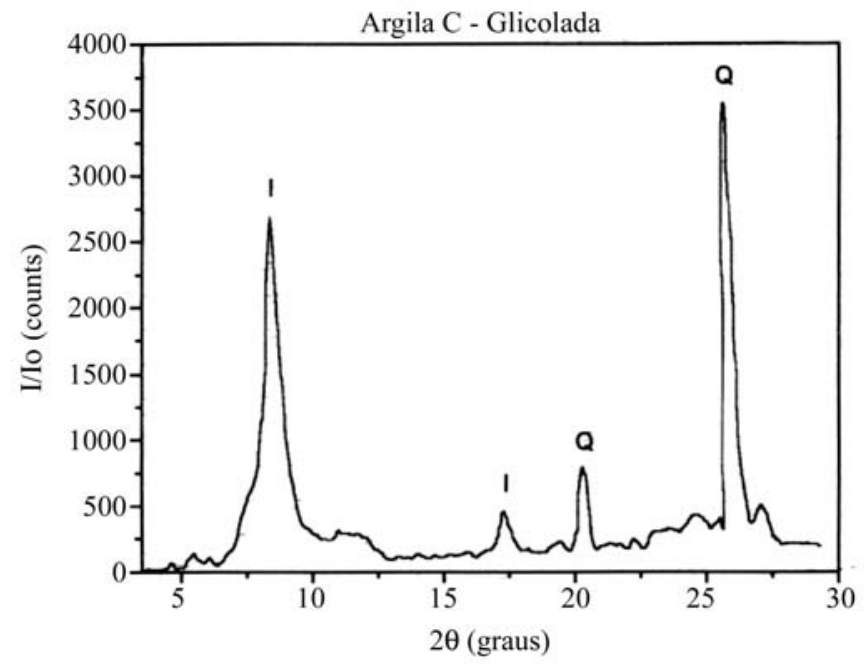

Figura 4: Difratograma da argila $\mathbf{C}$, após solvatação com etilenoglicol glicolagem (B). I: ilita, Q: quartzo.

[Figure 4: $X$-ray diffraction pattern of clay $\boldsymbol{C}$, following procedure (B). I: illite, $Q$ : quartz.]

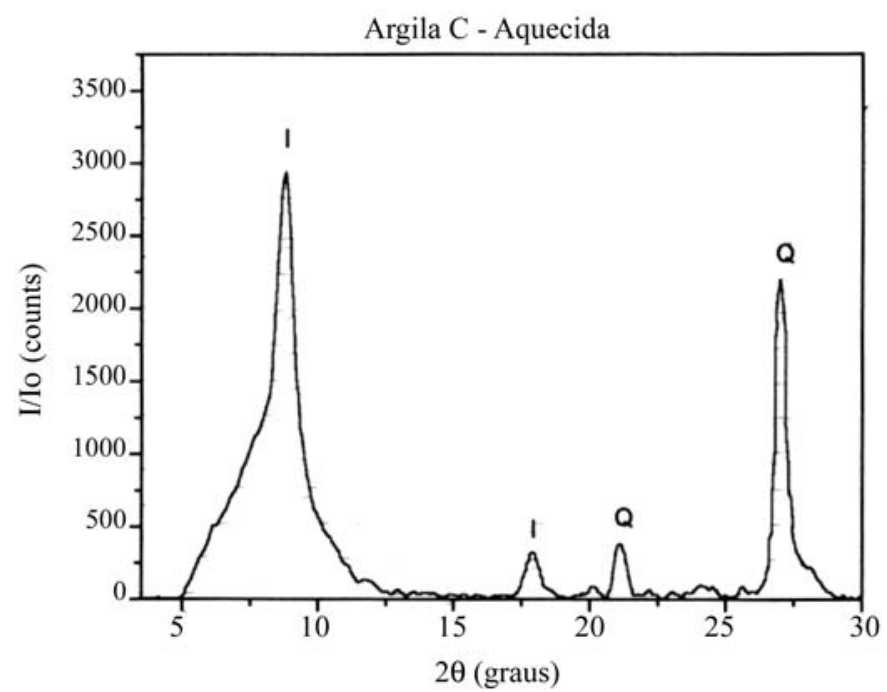

Figura 5: Difratogramada argila C, após aquecimentoda amostra(C). I: ilita, Q: quartzo. [Figure 5: X-ray diffraction pattern of clay $\boldsymbol{C}$, following procedure (C). I: illite, $Q$ : quartz.] 


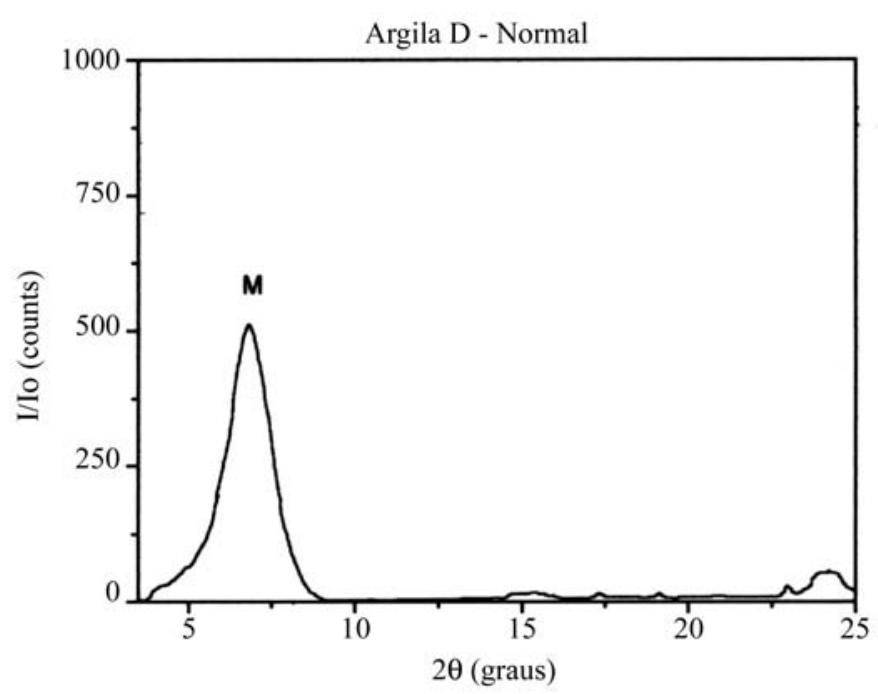

Figura 6: Difratograma da argila $\mathbf{D}$, seguindo o procedimento geral (A). M: montmorilonita.

[Figure 6: X-ray diffraction pattern of clay $\boldsymbol{D}$, following procedure (A). M: montmorillonite.]

com o procedimento geral (A).

Comparando-se os dados do difratograma com a Tabela I, constatou-se que tais picos são referentes à ilita, caulinita e quartzo.

As Figs. 3, 4 e 5 apresentam os difratogramas da argila $\mathbf{C}$, obtidos de acordo com o procedimento geral (A), após solvatação com etilenoglicol - gliconagem (B) e após aquecimento da amostra (C). Nas Figs. 3, 4 e 5 observa-se que não houve deslocamento dos picos, mesmo variando-se o procedimento de obtenção das lâminas (procedimento geral (A), glicolagem (B) e aquecimento da amostra (C)). Consultando as Tabelas I e II, identificou-se o argilomineral ilita.

As Figs. 6 e 7 apresentam os difratogramas da argila $\mathbf{D}$, obtidos de acordo com os procedimentos geral (A) e após solvatação com etilenoglicol - glicolagem (B).

De acordo com a Fig. 6 e Tabela I é possível identificar o argilomineral montmorilonita. Porém fez-se também o ensaio de difração de raios $X$ após glicolagem (Fig. 7) para confirmar o resultado obtido através do deslocamento do pico.

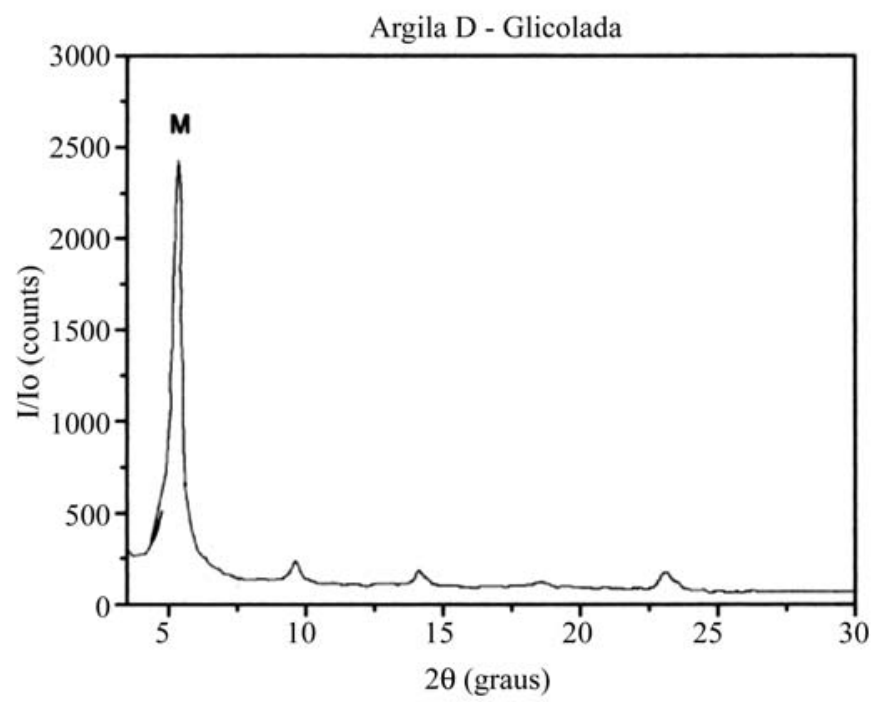

Figura 7: Difratograma da argila $\mathbf{D}$, após solvatação com etilenoglicol glicolagem (B). M: montmorilonita.

[Figure 7: X-ray diffraction pattern of clay $\boldsymbol{D}$, following procedure (B). M: montmorillonite.]

\section{CONCLUSÕES}

O procedimento para identificação de argilominerais por difração de raios $\mathrm{X}$ proposto neste trabalho permite a identificação rápida e confiável dos argilominerais comumente presentes em materiais argilosos no país.

\section{REFERÊNCIAS}

[1] L. E. Neves, "Estudo prático de argilas por difratometria de raios X" - Boletim Técnico da Petrobrás 11,1 (1968) 123-135.

[2] P. S. Santos, "Ciência e tecnologia de argilas v. 1". ed. Edgard Blücher Ltd. (1989).

[3] P. S. Santos, "Ciência e tecnologia de argilas v. 2". ed. Edgard Blücher Ltd. (1989).

(Rec. 20/02/02, Ac. 28/02/02) 